\title{
Determination of Total Phenolic, Flavonoid Content and Antimicrobial Properties in Different Solvent Extracts of Viburnum opulus L. (Gilaburu) in Afyonkarahisar
}

\author{
Mürüvvet Düz ${ }^{1}$, Safiye Elif Korcan ${ }^{2}$ and Gülderen Uysal Akkuş ${ }^{3}$ \\ ${ }^{1,3}$ Department of Chemistry, Afyon Kocatepe University, Afyonkarahisar, 03200, Turkey. \\ ${ }^{2}$ Vocational School of Health Services, Usak University, Usak, 64000, Turkey. \\ *Corresponding Author Email: guakkus@gmail.com \\ Received 20 October 2021, Revised 07 December 2021, Accepted 16 December 2021
}

\begin{abstract}
This study determined the antimicrobial and antioxidant activities of chloroform, ethyl acetate, methanol, and water extracts of the Viburnum opulus (V. opulus) plant. V. opulus (Gilaburu) was collected from Ahırdağı northern slope, Kırka Town, Afyonkarahisar region, and its leaves, branches, and fruit parts were dried and powdered at room temperature. The total phenolic content was compared with the gallic acid standard, the total flavonoid content with the quercetin standard, and the iron chelating effect with the EDTA standard. All extracts were evaluated for antimicrobial activity against Escherichia coli, Staphyllococcus aureus, and Candida glabrata strains by the agar well diffusion method. Gilaburu is widely used in Turkey, especially in alternative medicine. It has been determined that the fruit part of the plant has better antimicrobial properties, and the amount of phenolic compounds increases in more polar solvents. In conclusion, the use of Gilaburu as a medicinal drug can be achieved with new research on bioactive substances, especially in fruit extract.
\end{abstract}

Keywords: Viburnum opulus L., Gilaburu, Solvent, Antimicrobial activity, Antioxidant, Phenolic substance

\section{Introduction}

In Turkey, about 1000 plant species are used for therapeutic purposes, and $V$. opulus is one of these plants. It is known that the fruits, leaves, and bark are used as hemostatic and external vasotonic in diuretic, laxative, antispasmodic, sedative, gynaecological hemorrhages [1]. In this respect, it is necessary to scientifically investigate the effects and ways of action of these plants in order to use them in a healthy and efficient way. In recent years, antioxidant activity studies show that this species has antioxidant properties and is quite remarkable in terms of antioxidant levels [2,3].
It has been shown that sugars such as arabinose and rhamnose in Gilaburu stimulate the immune system by increasing lysosomal enzyme secretion and phagocytosis of macrophages in the peritoneum [4-6]. It has been revealed that Gilaburu contains gallic acid, protocatechuic acid, caffeic acid, pcoumaric acid, ellagic acid, and chlorogenic acids [7]. It has been reported that the chlorogenic acid content is $1.24 \%$, and the salicin acid content is $1.27 \%$ [8]. It has been reported that V.opulus is a source of flavonoids containing quercetin glycosides (+)-catechin, (-)epicatechin, and proanthocyanidin content and polyphenols at 
the rate of 6.80-8.29 $\mathrm{g}$ gallic acid/kg [9]. Two important groups of phenolic compounds are flavonoids and phenolic acids. Flavonoids are polyphenolic antioxidants found naturally in herbal teas, fruits, and vegetables. The main secondary metabolites with antioxidant activity in fruits are phenolic compound and ascorbic acid [10]. Zayachkivska et al. [11] understood that V.opulus has high antioxidant capacity due to the high amount of phenolic compounds in their study Gilaburu fruits contain high amounts of polyphenolic compounds [9, 12], L-malic acid, and ascorbic acid [12]. In addition, it was stated that cyanidin-3-glycoside, one of the anthocyanins contained in the fruit, is the most important factor in the identification of Gilaburu fruit [13]. The high phenolic concentration of these plant extracts also shows strong radical scavenging properties [14,15].

The presence of phenolic acids, tannins, coumarins, anthocyanins, iridoids and terpenes in the genus Viburnum has been reported so far [15]. It has been determined that the branches, leaves, and fruits of Gilaburu have high antioxidant activity because they contain abundant amentoflavone, salicin, and chlorogenic acid. It has been reported as a valuable plant for the food and pharmaceutical industry [16]. In this study, it is aimed to examine the antimicrobial properties of solvent extracts of Gilaburu collected in the Afyonkarahisar region.

\section{Materials and Methods Plant Collection and Identification}

$V$. opulus was collected from above Kirka town on the northern slope of Ahırdağ 1 /Afyonkarahisar. Description of the plant made by Dr. Mustafa Kargıoğlu of Art and Sciences Faculty, Department of Molecular Biology and Genetics. The leaves, branches, and fruit parts of the plant were cut into small pieces and dried in the shade at room temperature.

\section{Extraction of V. opulus with Soxhlet}

The dried parts of the plants were pulverized in a laboratory grinder. Cartridges were prepared separately from the powdered, woody branch and fruit samples of the plant. These prepared cartridges were extracted with chloroform, ethyl acetate, methanol, and water in a Soxhlet apparatus, respectively. Each time, $10 \mathrm{~g}$ of ground plant parts were taken into the cartridge, and $300 \mathrm{~mL}$ of solvent was added. In both cases, the extraction was continued for about $6 \mathrm{~h}$ until the solution in the Soxhlet apparatus became colorless. Extracts obtained by the Soxhlet device were filtered through filter paper and their solvents were removed with a rotary evaporator. The prepared extracts were stored in the dark, capped glass bottles at $+4{ }^{\circ} \mathrm{C}$, and then their antioxidant and antimicrobial activities were determined.

Table 1. Abbreviations of extracts.

\begin{tabular}{lc}
\hline Abbreviation & V. Opulus Extracts \\
\hline VOFC & Viburnum opulus Fruit Chloroform \\
VOFEA & Viburnumopulus Fruit Ethyl acetate \\
VOFM & Viburnum opulus Fruit Methanol \\
VOFW & Vibumum opulus Fruit Water \\
VOLC & Viburnum opulus Leaf Chloroform \\
VOLEA & Viburnum opulus Leaf Ethyl acetate \\
VOLM & Viburnum opulus Leaf Methanol \\
VOLW & Viburnumopulus Leaf Water \\
VOBC & Viburnumopulus Branch Chloroform \\
VOBEA & Viburnumopulus Branch Ethyl acetate \\
VOBM & Viburnum opulus Branch Methanol \\
\hline
\end{tabular}




\section{Determination of Total Flavonoid Content}

The total flavonoid content of plant extracts was determined by $\mathrm{AlCl}_{3} / \mathrm{CH}_{3} \mathrm{COO}^{-}$ $\mathrm{K}^{+}$spectrophotometric method [17, 18]. The calibration curve was obtained with different concentrations of quercetin. Samples to be tested $(1 \mathrm{mg} / \mathrm{mL})$ were prepared in methanol. $1.5 \mathrm{~mL}$ of methanol, $0.1 \mathrm{~mL}$ of $10 \%$ $\mathrm{AlCl}_{3} \cdot 6 \mathrm{H}_{2} \mathrm{O}$ solution, and $0.1 \mathrm{~mL}$ of $1 \mathrm{M}$ $\mathrm{CH}_{3} \mathrm{COO}^{-} \mathrm{K}^{+}$solution were added to $0.5 \mathrm{~mL}$ of the sample solution in a glass tube, respectively, and the tube was then shaken well. After $30 \mathrm{~min}$ of incubation at room temperature, their absorbance at a wavelength of $415 \mathrm{~nm}$ was measured with a UV/visible spectrophotometer (Thermo Scientific Evolution 201). Results are given as $\mathrm{mg}$ quercetin/g extracts equivalent.

\section{Determination of Total Phenolic Content}

The Folin-Ciocalteu reaction is an electron transfer-based antioxidant assay that measures the reducing capacity of an antioxidant. The principle of the method is that phenolic compounds dissolved in water and organic solvents form colored complexes with Folin reagents in an alkaline medium. The resulting purple-violet complex creates a maximum absorbance at $765 \mathrm{~nm}$ [19]. FolinCiocalteu reagent was added to the prepared plant extracts and standard antioxidant substances. $\mathrm{Na}_{2} \mathrm{CO}_{3}$ was added and kept at room temperature for $2 \mathrm{~h}$, and then the absorbance of the mixture was measured at $760 \mathrm{~nm}$ against water. Gallic acid was used as the standard for the calibration curve, and the results were determined as gallic acid equivalents [19].

\section{Metal Chelating Activity}

The chelating capacity of $\mathrm{Fe}^{2+}$ ions of samples according to the method specified by Dinis et al. [20]. The reaction was started by adding $1 \mathrm{~mL}$ of extract $(1 \mathrm{mg} / \mathrm{mL}), 3.2 \mathrm{~mL}$ of distilled water $2 \mathrm{mM} \mathrm{FeCl} 2(0.1 \mathrm{~mL})$, and 5 $\mathrm{mM}$ ferrozine $(0.2 \mathrm{~mL})$. After mixing the solution, it was incubated for $10 \mathrm{~min}$ at room temperature, and then its absorbance was measured at $562 \mathrm{~nm}$. EDTA was used as a positive control in this assay system. The percent inhibition of ferrozine $\mathrm{Fe}^{2+}$ complex formation was calculated using the following equation:

Metal chelating capacity $(\%)=[($ A control A sample) / A control] $\times 100$

\section{Agar Well Diffusion Test}

The antimicrobial activity of the plant extracts was studied by the agar well diffusion method [21]. E. coli ATCC 25922, S. aureus ATCC 25923, and $C$. glabrata strains were used in antimicrobial activity experiments. The samples to be tested were weighed $0.05 \mathrm{~g}$ and dissolved in DMSO. The standard strains used in these tests were obtained from the Uşak University Vocational School of Health Services, Department of Medical Services and Techniques Research Laboratory. The studies were carried out in the same laboratory.

Bacteria culture was prepared at a density of 0.5 Mac Farland in NB (Nutrient broth). $100 \mu \mathrm{L}$ of the microbial suspension taken from the bacterial culture was inoculated onto Mueller Hilton Agar (MHA) by spreading it well over the entire agar surface with a sterile swab. Each plate was drilled to create $6 \mathrm{~mm}$ diameter wells with the help of a sterile cork drill at different parts of the plates. Then, $50 \mu \mathrm{L}$ of each of the extracts and solvent (used as the negative control group) were pipetted into the wells of the assay plates and incubated at $37^{\circ} \mathrm{C}$ for $24 \mathrm{~h}$. Vancomycin $(30 \mu \mathrm{g})$, Chloramphenicol (30 $\mu \mathrm{g})$, Penicillin $(10 \mu \mathrm{g})$, Tetracycline $(30 \mu \mathrm{g})$ and Erythromycin $(15 \mu \mathrm{g})$ were used as positive controls. Zones of inhibition were measured after incubation [22]. 
Results and Discussion

\section{Total Phenolic Content, Total Flavonoid Content}

The total phenolic content of the extracts was determined as $\mathrm{mg}$ gallic acid equivalent (GAE) per gram of sample in dry weight $(\mathrm{mg} / \mathrm{g})\left(\mathrm{y}=0.0013 \mathrm{x}+0.0492 \mathrm{R}^{2}=\right.$ 0.9979) (Fig. 1). The total phenolic compound and flavonoid content in the extracts obtained from the leaves, branches, and fruit parts of V.opulus with 5 different solvents are given in Table 2.

Table 2. Total Phenolic Compound and Total Flavonoid Content.

\begin{tabular}{lccc}
\hline $\begin{array}{c}\text { V. } \\
\text { Opulus }\end{array}$ & Extract & $\begin{array}{c}\text { Total Phenolic } \\
\text { Content } \\
\text { mg GAE/g } \\
\text { extract }\end{array}$ & $\begin{array}{c}\text { Total Flavonoid } \\
\text { Content mg } \\
\text { quercetin/g extract }\end{array}$ \\
\hline \multirow{4}{*}{ Fruit } & VOFC & $38.31 \pm 0.01$ & $0.05 \pm 0.01$ \\
& VOFEA & $101.38 \pm 0.01$ & $0.04 \pm 0.02$ \\
& VOFM & $50.62 \pm 0.01$ & $0.007 \pm 0.03$ \\
& VOFW & $99.85 \pm 0.03$ & $0.02 \pm 0.01$ \\
\hline \multirow{3}{*}{ Leaf } & VOLC & $3.69 \pm 0.02$ & $0.12 \pm 0.01$ \\
& VOLEA & $10.62 \pm 0.01$ & $0.13 \pm 0.01$ \\
& VOLM & $61.38 \pm 0.01$ & $0.10 \pm 0.01$ \\
& VOLW & $51.38 \pm 0.01$ & $0.06 \pm 0.21$ \\
\hline \multirow{3}{*}{ Branch } & VOBC & $103.69 \pm 0.09$ & $0.08 \pm 0.03$ \\
& VOBEA & $104.46 \pm 0.05$ & $0.10 \pm 0.02$ \\
& VOBM & $127.53 \pm 0.04$ & $0.06 \pm 0.01$ \\
& VOBW & $146.76 \pm 0.01$ & $0.05 \pm 0.41$ \\
\hline
\end{tabular}

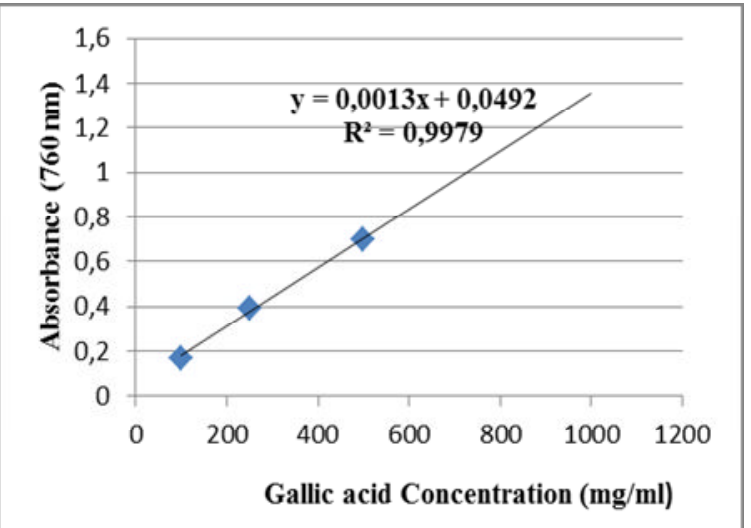

Figure 1. The graph of the absorbance values given at $760 \mathrm{~nm}$ against different concentrations of gallic acid Total flavonoid contents were determined as $\mathbf{m g}$ quercetin/g extract equi valents according to the equation $y=6.6684 x+0.0663 R^{2}=0.9979$ obtained with the calibration curve.

\section{Metal Ion Chelating Activity}

Metal ion chelating activity was evaluated according to the competition of plant extracts with ferrozine to bind $\mathrm{Fe}^{2+}$ ions in the solution. EDTA $(1 \mathrm{mg} / \mathrm{mL})$ was used as a standard. Metal chelating activity results are given in Table 3.

Table 3. Metal ion chelating activity.

\begin{tabular}{|c|c|c|}
\hline V. Opulus & Extract & $\begin{array}{c}\text { Iron Chelating Effect } \\
(\%)\end{array}$ \\
\hline \multirow{5}{*}{ Fruit } & VOFC & $14.3 \pm 0.17$ \\
\hline & VOFEA & $16.69 \pm 0.09$ \\
\hline & & \\
\hline & VOFM & $20.59 \pm 0.04$ \\
\hline & VOFW & $13.20 \pm 0.35$ \\
\hline \multirow{5}{*}{ Leaf } & VOLC & $10.13 \pm 0.09$ \\
\hline & VOLEA & $14.36 \pm 0.00$ \\
\hline & & \\
\hline & VOLM & $16.18 \pm 0.04$ \\
\hline & VOLW & $16.67 \pm 0.04$ \\
\hline \multirow{5}{*}{ Branch } & VOBC & $13.63 \pm 0.00$ \\
\hline & VOBEA & $11.02 \pm 0.04$ \\
\hline & VOBM & $16.24 \pm 0.13$ \\
\hline & VOBW & $17.96 \pm 0.04$ \\
\hline & EDTA $(1 \mathrm{mg} / \mathrm{mL})$ & $82.23 \pm 0.04$ \\
\hline
\end{tabular}

\section{Antimicrobial Activity Assay}

The antimicrobial activity results of the leaves, branches and fruit parts of the V.opulus are given in Table 4. As a result of the experiments, it was determined that except VOBW extract, the other one showed antimicrobial activity against $S$. aureus. It has been observed that VOFC extract $(35 \mathrm{~mm})$ has a stronger effect against $S$. aureus than antibiotics other than penicillin. Only VOLW and VOFEA extracts showed fungicidal activity against $C$. glabrata. 
Table 4. Inhibition diameter ( $\mathrm{mm})$ of $V$. opulus extracts by Agar wells method.

\begin{tabular}{llccc}
\hline \multirow{6}{*}{ Controls } & \multicolumn{3}{c}{ Bacteria } \\
\cline { 3 - 5 } & & S. aureus & E. coli & C. glabrata \\
\hline \multirow{6}{*}{ VA (30) } & 21 & 25 & 8 \\
& P (10) & 40 & 33 & 7 \\
& C (30) & 27 & 30 & 28 \\
& E (15) & 30 & 26 & - \\
& TE (30) & 30 & 12 & 19 \\
\hline Extracts & Samples & & & \\
\hline \multirow{5}{*}{ Fruit } & VOFC & 35 & - & 13 \\
& VOFEA & 22 & - & - \\
& VOFM & 13 & - & - \\
& VOFW & 14 & - & - \\
\hline \multirow{5}{*}{ Leaf } & VOLC & 9 & - & - \\
& VOLEA & 11 & - & - \\
& VOLM & 13 & - & - \\
& VOLW & 12 & - & - \\
\hline \multirow{5}{*}{ Branch } & VOBC & 12 & - & - \\
& VOBEA & 9 & - & - \\
& VOBM & 11 & - & - \\
& VOBW & - & - & 10 \\
\hline
\end{tabular}

VA (30) Vancomycin, P (10) Penicillin, C (30) Chloramphenicol, E (15) Erythromycin, Te (30) Tetracycline

The most important secondary metabolites in plants are phenolic compounds, alkaloids, and terpenes. Phenolic compounds also have antimicrobial, antioxidative, and anticarcinogenic activities, especially terpenes; It is effective against bacteria and viruses [23]. Flavonoids, biflavonoids, and coumarins have been reported in different Viburnum species $[24,25]$. In our study, when the total phenolic content of the studied extracts of V.opulus was compared, it was determined that the branch extracts had the most phenolic content. The lowest phenolic content was observed in the leaf chloroform extract $(3.69 \pm 0.02 \mathrm{mg} \mathrm{GAE} / \mathrm{g}$ extract), while the highest phenolic content was found in the branch water extract $(146.76 \pm 0.01 \mathrm{mg} \mathrm{GAE} / \mathrm{g}$ extract).

These results are in agreement with the literature. Kajszczak et al. [27] reported that studies on the phenolic profile of V.opulus were very infrequent when comparing $V$. opulus fruit with other morphological parts. Erdogan et al. [15] determined the total phenol content in methanol extracts of branches $(217.95 \pm 1.29 \mathrm{mg}$ GAE$/ \mathrm{g}$ extract), leaves $(132.11 \pm 1.89 \mathrm{mg} \mathrm{GAE} / \mathrm{g}$ extract), and fruits $(147.39 \pm 1.85 \mathrm{mg} \mathrm{GAE} / \mathrm{g}$ extract) at a higher rate than the ethyl acetate and water extracts of V.opulus.

Flavonoids are plant phytochemicals that humans cannot synthesize. Flavonoids are thought to have health-promoting properties due to their high antioxidant capacity and may help reduce inflammation, form healthy blood vessels, prevent cell damage, and delay aging [26]. Total flavonoids in $V$. opulus fruits have been reported to constitute $21.73 \%$ to $57.16 \%$ of the total phenolic compound content, with 187 to $489 \mathrm{~g}$ per $100 \mathrm{~g}$ fresh weight. In seeds, bark, and flowers of $V$. opulus, flavonoids constitute $83.86 \%, 56.53 \%$, and $47.58 \%$ of total phenolics, respectively [27]. Rop et al. [9] determined the total flavonoid content in fresh fruits of V.opulus in the range of 3.14 to $4.89 \mathrm{~g} / \mathrm{kg}$ (314 to $489 \mathrm{mg} / 100 \mathrm{~g}$ ). Polka et al. [28] reported that total flavonoids varied from 1.67 (flowers) to 2.25 (bark) $\mathrm{g}$ (+)-catechin equivalents/100g DW, and Flavonoids accounted for 47.6, 53.9 and $56.5 \%$ of total phenolics in VO flowers, fruits and bark, respectively. In our study, the total flavonoid content was found to be high, especially in leaf ethyl acetate extracts VOLEA, $0.13 \pm 0.01 \mathrm{mg}$ quercetin/g extract. It was seen that fruit extracts contain lower total flavonoids compared to branch and leaf extracts. In addition, when comparing the measurement results with other studies, the use of different methods and standards, as well as the use of different units, showed that there were differences between the studies.

Free radical scavenging activities of the extracts were defined by the metal chelation method using ferrozine radical, and all extracts were evaluated. Erdogan et al. [15] reported that the leaf EtOAc (VOLEA) extract 
of $V$. opulus $(33.01 \%)$ had remarkable ferrous ion chelating capacity, but the remaining branch and fruit extracts did not have the capacity to chelate iron ions. In this study, it was decided that none of the different solvent extracts of the plant could reach as high efficacy as EDTA. While the highest iron chelating effect was observed in VOFM (20.59\%) extract, the lowest effect was observed in VOLC $(10.13 \%)$ extract.

Identification of plant extracts with antimicrobial properties is indicated as a safe and effective way to control clinical infections [29]. It has been determined by some studies that antimicrobial activity is high in the dried fruits and seeds of the V.opulus plant [30, 31]. Eryılmaz et al. [32] tested the antimicrobial activities of aqueous and ethanolic extracts of 4 different Viburnum species against six bacteria and one yeast. They stated that ethanolic extracts exhibited better antimicrobial activity than aqueous extracts. The aqueous extracts obtained from the stem, flower, and leaf of VO did not show antibacterial and antifungal activities. Turker et al. [33] obtained the best antibacterial activity from dried fruit extracts with hot water. It inhibited the growth of Staphylococcus aureus ATCC 25923, Staphylococcus epidermidis ATCC 12228, and Streptococcus pyogenes ATCC 19615.

Zakłos-Szyda et al. [34] reported that Grampositive pathogenic bacteria (i.e., Staphylococcus aureus ATTC 6538, Enterobacter faecalis ATCC 29212, Listeria monocytogenes ATCC 19115) are more susceptible to $\mathrm{VO}$ fruit components than Gram-negative bacteria. It has been reported in the studies that the antibacterial effect observed in VO fruit juices is due to chlorogenic acid and procyanidins on the metabolism affecting the bacterial cell wall and membrane stiffness, permeability or integrity.
Vijaytha et al. [18] reported that $V$. coriaceum blume plant root methanol extract showed significant inhibition in agar gel well diffusion assay containing many microorganisms. According to Yilmaz et al. [31] V. opulus, V. lantana, and V. orientala tested for antimicrobial activity against $E$. coli, $K$. pneumoniae, $P$. aeruginosa, $E$. faecalis, $S$. aureus, B. cereus bacteria, and fungi $C$. tropicalis at maximum essential oil concentrations of 250,500 and $1000 \mu \mathrm{g} / \mathrm{mL}$, respectively. However, no activity was observed against all test microorganisms for $V$. lantana and $V$. opulus.

In our study, the antimicrobial properties of the fruit, leaf, and branch parts of the plant were investigated in different solvent systems using chloroform, ethyl acetate, methanol, and water extracts. As a result, it was determined that all samples except VOBW extracts had effects against $S$. aureus bacteria, but the most antimicrobial effect was in the VOFC extract. These results are consistent with the literature, Cesoniene et al. [12] compared $V$. opulus fruit juices and ethanol extracts and reported that fruit juices have higher antimicrobial activity and therefore $V$. opulus fruit can be used as a potential source of antibacterial drugs. It was determined that this situation was also found in the chloroform extract of the fruit of the V.opulus plant that we used in our study.

\section{Conclusion}

It has been determined that most of the studies on the V.opulus plant were performed on the fruit, and limited documents were related to other morphological parts of the plant, such as branches, bark, leaves, or flowers. For this reason, in this study, the fruit, leaf, and branch parts of the plant grown in the Afyon region were studied in different solvent polarities, and their antimicrobial and antioxidant properties were revealed. As a 
result, it can be said that the fruit part of the plant has better antimicrobial properties, the amount of phenolic compounds increases in more polar solvents, and the iron chelating effect is negligible. Antimicrobial new drugs can be obtained by purifying the fruit extract of the plant by chromatographic methods and analyzing its structure.

\section{Conflict of Interest}

The authors declare that there is no conflict of interest.

\section{References}

1. R. Yıldız, H. Ekici, Bull. Vet. Pharm. Tox., 10 (2019) 16

ISSN: 1309-4769

2. L. M. Altun, S. G. Çitoğlu, B .S. Yilmaz and T. Çoban, Int. J. Food Sci. Nutr., 59 (2008) 175.

https://doi.org/10.1080/09637480701381 648

3. I. E. Orhan, M. L. Altun, B. S. Yilmaz and G. Saltan, J. Med. Food, 14 (2011) 4.

https://doi.org/10.1089/jmf.2010.0053

4. R. G. Ovodova, V. V. Golovchenko, S. V. Popov, A. S. Shashkov and I. S. Ovodov, Russ. J. Bioorg. Chem., 26 (2000) 54.

https://doi.org/10.1007/BF02758861

5. A. Aksoy, A. Güvensan, E. Akçiçek and M. Oztürk, International Symposium on Medicinal Plants: Linkages Beyond National Boundaries, 7-9 September Islamabad, Pakistan (2004) 65.

6. M. Çam and Y. Hişil, Acta Aliment., 36 (2007) 381 .

https://doi.org/10.1556/aalim.36.2007.3.10

7. S. Turek and W. Cisowski, Acta Pol. Pharm., 64 (2007) 377.

PMID: 18536165

8. M. I. Altun and B. S. Yilmaz, Chem. Nat. Compd., 43 (2007) 205. https://doi.org/10.1007/s10600-0070079-0

9. O. Rop, V. Reznicek, M. Valsikova, T. Jurikova, J. Mlcek and D. Kramarova, Molecules, 15 (2010) 4467.

https://doi.org/10.3390/molecules 15064467

10. E. Ulger, H. Ertekin, O. Karaca, O. Canoz, M. Nisari, E. Unur and F. Elmalı, Toxicol. Ind. Health, 29 (2012) 824. doi: 10.1177/0748233712445049

11. O. S. Zayachkivska, M. R. Gzhegotsky, O. I. Terletska, D. A. Lutsyk,, A. M. Yaschenko and O. R. Dzhura, J. Physiol. Pharmacol., 57 (2006) 155.

PMID: 17218766.

12. L. Cesonienè, R. Daubaras, P. Viškelis and A. Sarkinas, Plant Foods Hum. Nutr., 67 (2012) 256. https://doi.org/10.1007/s11130-0120303-3

13. V. I. Deineka, V. N. Sorokopudov, L. A. Deineka, E. I. Shaposhnik and S. V. Koltsov, Chem. Nat. Compd., 41 (2005) 162.

https://doi.org/10.1007/s10600-00501022

14. O. Sağdıç, A. Aksoy and G. Özkan, Acta Aliment., 35 (2006) 487 https://doi.org/10.1556/aalim.35.2006.4.12

15. I. Erdogan-Orhan, M. L. Altun, B. Sever-Yilmaz and G. Saltan, J. Med. Food, 14 (2011) 434.

doi: 10.1089/jmf.2010.0053

16. L. Česonienè, R. Daubaras, V. Kraujalytė, J. Verbr. Lebensm, 9 (2014) 129.

https://doi.org/10.1007/s00003-0140864-1

17. C. C. Chang, M. H. Yang, H. M. Wen and J. C. Chern, J. Food Drug. Anal., 10 (2002) 178. doi: 10.3923/rjphyto.2016.67.74

18. V. Vijaytha, R. V. Anupama and M. Haridas, Future J. Pharm. Sci., 6 (2020) 84.

https://doi.org/10.1186/s43094-020$\underline{00098-y}$ 
19. K. Slinkard and V. L. Singleton. Am. J. Enol. Viticult., 28 (1977) 49. https://www.ajevonline.org/content/28/1/49

20. T. C. Dinis, V. M. Maderia and L. M. Almeida, Arch. Biochem. Biophys., 15 (1994) 161.

doi: 10.1006/abbi.1994.1485

21. B.Mounyr, S. Moulay Ibnsouda and S. Koraichi, J. Pharm. Anal., 6 (2016) 71. https://doi.org/10.1016/j.jpha.2015.11.005 .

22. G. Chavez-Esquivel, H. CervantesCuevas, L. F. Ybieta-Olvera, M. T. Castañeda Briones, D. Acosta and J. Cabello, Mater. Sci. Eng. C, 123 (2021) 111934.

https://doi.org/10.1016/j.msec.2021.111 $\underline{934}$

23. S. Hakkinan, Flavonols and phenolic acids in berries and berry products. Kuopia University Publications, D. Medical Scienses-Doctora Thesis, (2000).

24. J. S. Glasby, Dictionary of plants containing secondary metabolites. Taylor and Francis, Basingstoke, London (1991) 336. ISBN: 9780850664232

25. V. Plouvier, Bulletin du Museum National d'Histoire Naturelle (vols. 3-4 e ser. section B). Paris, Adansonia, (1992) 461.

26. A. Kahraman, M. Serteser and T. Koken, Med. J. Kocatepe, 3 (2002) 1. doi: $10.18229 / \mathrm{ktd} .98138$
27. D. Kajszczak, Z. S. Małgorzata and P. Anna, Nutrients, 12 (2020) 3398. https://doi.org/10.3390/nu 12113398

28. D. Polka, A. Podsędek, M.Koziołkiewicz, Plant Foods Hum. Nutr., 74 (2019) 436. https://doi.org/10.1007/s11130-01900759-1

29. D. Savoia, Future Microbiol., 7 (2012) 979.

doi: $10.2217 / \mathrm{fmb} .12 .68$

30. O. Sagdic, A. Aksoy and G. Ozkan, Acta Aliment. Hung., 35 (2006) 487. http://dx.doi.org/10.1556/AAlim.35.200 6.4 .12

31. N. Y1lmaz, N. Yayl1, M. Guelbin, Chem. Asian J., 20 (2008) 3324.

ISSN: 09707077

32. M. Eryılmaz, S. Ozbilgin, B. Ergene, B Yilmaz, M. Altun and G. Citoglu, Bangladesh J. Bot., 42 (2013) 355. https://doi.org/10.3329/bjb.v42i2.18044

33. H. Turker and A. Birinci Yildirim, Biotechnol. Biotechnol. Equip., 29 (2015) 281. doi:10.1080/13102818.2015.1006445

34. M. Zakłos-Szyda, A. Nowak, N.Pietrzyk and A. Podsedek, Int. J. Mol. Sci., 21 (2020) 4909. https://doi.org/10.3390/ijms21144909 